\title{
Competências Profissionais e Classe de Comportamentos Requeridos no Mercado de Trabalho nos Meios de Hospedagem
}

\author{
Professional Competences and Class of Behaviors Required in the Work of Lodging \\ Facilities
}

\section{Competencias Profesionales y Clases de Comportamientos Requeridos en el Mercado de Trabajo en Instalaciones de Hospedaje}

Creici Lamonato ${ }^{1}$

Nadi Helena Presser ${ }^{2}$

\begin{abstract}
Resumo
Delineia as competências profissionais requeridas na execução das tarefas dos trabalhadores que atuam nos meios de hospedagem, por meio da decomposição da classe de comportamentos que determinado cargo demanda. Pesquisa descritiva, coletou dados de 52 vagas de trabalho anunciadas em cinco sites de divulgação de vagas nacionais: Sine, Catho, Indeed, Pense Emprego e Manager. Os dados foram classificados e analisados de acordo com as variáveis dispostas nos anúncios de vagas de empregos analisados. O estudo identificou dez classes de comportamentos, as quais foram traduzidas em diversas classes de comportamentos intermediários dos cargos: comunicar-se com o cliente, relacionar-se com o cliente, agir com proatividade, organizar as atividades, atuar com agilidade, concentrar-se para solução de problemas, trabalhar em equipe, planejar ações, realizar as atividades técnicamente, e liderar com foco para o resultado. Igualmente, no que se refere à escolaridade, o estudo constatou que $73 \%$ das vagas do nível operacional e gerencial primam pela absorção de profissionais que possuam no mínimo ensino médio ou superior, porém apenas seis vagas de nível superior solicitam formação na área de Hotelaria, Turismo e Gastronomia. O estudo também apontou que somente $27 \%$ das vagas requerem profissionais com domínio de outros idiomas.
\end{abstract}

Palavras-chave: Competência profissional; Classe de comportamento; Mercado de trabalho; Meios de hospedagem.

\begin{abstract}
This research outlines the professional competences required for the execution of tasks for those who work in lodging facilities. The research was carried out through the decomposition of the class of behaviors which a given position in the area demands. Descriptive research

\footnotetext{
${ }^{1}$ Docente na Faculdade Senac Chapecó e na Universidade do Oeste de Santa Catarina. Mestre em Psicologia pela Universidade Federal de Santa Catarina. Chapecó-SC, Brasil. E-mail: creici-lamonato@hotmail.com

2 Docente do Mestrado em Gestão Pública e do Programa de Pós-Graduação em Ciência da Informação da Universidade Federal de Pernambuco. Pós-doutoranda em Ciência da Informação na Universidade Carlos III de Madrid. Recife-PE, Brasil. E-mail: nadihelena@uol.com.br
} 
that collected data from 52 job vacancies advertised in five sites announcing national vacancies: Sine, Catho, Indeed, Pense Emprego, and Manager. Data was classified and analyzed according to the variables presented in the advertisings for the jobs studied. As main results the study identified ten classes of behaviors: communicate with clients, relate to clients, proactivity, organize activities, act with agility concentrate on the solutions of problems, work in a team, plan actions, carry out activities technically and lead focusing on results. These ten classes of behavior were translated in various classes of intermediary behaviors of positions. Regarding levels of formal education, the study found that $73 \%$ of the vacancies in the operational and managerial level hire professionals who have at least secondary school level or higher education. Only six vacancies requiring higher education demanded for a degree in the area of hotel, tourism and gastronomy. The study also showed that only $27 \%$ of the vacancies required professionals who mastered foreign languages.

Keywords: Professional competence; Class of behavior; Work market; Lodging facilities.

\section{Resumen}

Describe las competencias profesionales que requieren los trabajadores que actúan en instalaciones de alojamiento, a través de la descomposición de las clases de comportamientos que demanda cada cargo en particular. Este estudio descriptivo recogió datos de 52 vacantes de trabajo, anunciadas en cinco sitios de divulgación nacionales: Sine, Catho, Indeed, Pense Emprego, y Manager. Los datos fueron clasificados y analizados de acuerdo con las variables disponibles en los anuncios analizados. El estudio identificó diez clases de comportamientos - comunicarse con el cliente, relacionarse con el cliente, actuar de forma proactiva, organizar actividades, actuar con agilidad, enfoque para la resolución de problemas, trabajo en equipo, planificar acciones, realizar las actividades técnicamente, y liderar con especial atención en el resultado - que se tradujeron en varias clases de comportamientos intermediarios de cargos. Con respecto a la escolaridad, el estudio encontró que el $73 \%$ de las vacantes de nivel operacional y de gestión requieren profesionales que tengan al menos educación secundaria o superior, aunque sólo seis vacantes de nivel superior solicitaban formación en el área de Hotelería, Turismo y Gastronomía. El estudio también encontró que sólo el $27 \%$ de las vacantes requieren profesionales con dominio de otros idiomas.

Palabras clave: Competencia profesional; Clase de comportamiento; Mercado de trabajo; Medios de hospedaje

\section{Introdução}

As organizações estão cada dia mais preocupadas em se diferenciar no mercado de trabalho em virtude da necessidade de se manterem competitivas em relação à concorrência. Formar uma equipe de trabalho para atuar nesse mercado pode se traduzir numa vantagem competitiva, pois são as pessoas que possuem capacidade de transformar os recursos organizacionais em resultados 
positivos. Diante disso, parece ser fundamental a contratação de profissionais que atendam a um conjunto de competências requerido para cada cargo nas organizações.

A atração e seleção de pessoas pressupõem a definição do conjunto de competências necessárias para a realização das atividades de um cargo. Ter consciência do perfil profissional desejado é estabelecer quais são os conhecimentos, habilidade, atitudes e experiências esperadas para uma atuação adequada. Quando isso não é realizado, pode gerar uma variedade de implicações organizacionais tais como seleção de profissionais que não atendem às demandas do cargo, inadaptação ao trabalho, rotatividade, rotação de cargos, dentre outras.

Nos meios de hospedagem, a definição das competências para atuar num determinado cargo parece se tornar mais relevante, em virtude da atuação direta dos profissionais com os clientes, os quais almejam serviços de qualidade. Mas quais são os comportamentos mais requisitados para os cargos anunciados nos meios de hospedagem? A fim de responder essa questão foi realizado um estudo para delinear as competências profissionais requeridas na execução das tarefas dos trabalhadores que atuam nos meios de hospedagem, por meio da decomposição da classe de comportamentos que determinado cargo demanda.

\section{Competências Profissionais e Classes de Comportamentos Demandadas ao Profissional nos Meios de Hospedagem}

À primeira vista, uma das competências profissionais necessárias para a execução de atividades de um cargo nos meios de hospedagem é saber se comunicar, ação que está mais perceptível e visível. No entanto, um cargo exige uma variedade de ações que nem sempre são perceptíveis, a menos que se faça uma decomposição dessas competências.

Muitas são as definições de competência na literatura. Historicamente, conforme Santos et al. (2009, p. 132), "a palavra competência é utilizada em diferentes contextos e como referência a diversos fenômenos", desde empresas, nas quais a competência está relacionada à capacidade de realizar determinadas tarefas no trabalho (ISAMBERT-JAMATI, 1997; SANTOS et al., 2009), até escolas, referindo-se ao trabalho de produção de aprendizagens, como o fez o educador Perrenoud (2001), um dos primeiros pesquisadores da área da educação a estudar o tema.

Segundo o dicionário de verbetes em educação de Menezes e Santos (2002), competência é um conjunto de conhecimentos (saberes), habilidades (saber fazer) e atitudes (saber ser), os 
quais permitem ao indivíduo desempenhar determinadas tarefas. O conhecimento está relacionado àquilo que se sabe, ao saber que a pessoa acumulou ao longo de sua vida. As habilidades dizem respeito àquilo que se sabe fazer, à capacidade da pessoa de utilizar seus conhecimentos na ação. As atitudes, por sua vez, referem-se àquilo que se aspira fazer, ou, como diz Durand (2000), referem-se aos aspectos sociais e afetivos relacionados ao trabalho. Dito de outra forma, ser competente requer a capacidade de alcançar resultados, transformando conhecimentos em habilidades, por meio de atitudes e comportamentos adequados. Como já disseram Botomé e Kubo (2002), somente o conteúdo não é mais suficiente, é preciso desenvolver também a capacidade de atuar.

Definir competência não é uma tarefa simples, considerando-se os inúmeros conceitos apresentados na literatura. Bitencourt e Barbosa (2010) listaram 20 conceitos de diferentes autores sobre o que significa competência e verificaram que as definições diferem entre si por sua ênfase e pela função atribuída a cada conceito. Nesse sentido, não é somente um problema de conceituação, mas também de explicitação das variadas funções a que esse fenômeno se refere. O termo, por exemplo, pode ser utilizado para se referir às necessidades de um cargo, ou às competências apresentadas pelo indivíduo em um processo avaliativo.

Segundo Junior et al. (2009), as competências podem ser classificadas em três grupos: competências individuais e sociais, competências específicas e competências organizacionais. As competências individuais e sociais estão relacionadas ao comportamento das pessoas, como, por exemplo, à capacidade de negociar. As competências específicas são aquelas que envolvem diversas áreas do conhecimento e que são aprendidas por meio da interação com outros indivíduos, ou meio de outros recursos (Internet, livro). As competências organizacionais são representadas pelo conjunto de processos, funções, tecnologias, normas e talentos. Verifica-se na classificação realizada pelo autor a diversidade de funções a que o termo "competências" pode estar associado.

Para Le Bortef (1994) a competência está vinculada ao conceito de fazer, à habilidade de concretizar uma ação. Parry (1996) define competência como um conjunto de conhecimentos, habilidades e atitudes que afetam o trabalho e desempenho de uma pessoa. Na mesma linha, Santos et al. (2009) observam que a competência indica a qualidade daquilo que é realizado. "Quanto mais eficaz é uma ação, mais competentes as pessoas são ou mais 'competências' elas têm." (SANTOS et al., 2009, p. 133). O destaque, segundo esses autores, está “(...) nos 
efeitos das ações de alguém sobre determinado contexto ou situação, mais do que nas características de forma dessas ações." (SANTOS et al., 2009, p. 133).

Para Bitencourt e Barbosa (2010) as dimensões saber (conhecimento), saber fazer (habilidades) e saber agir (atitudes) estão relacionadas entre si e se confundem em virtude de que essas dimensões poderem ser analisadas de diferentes perspectivas, como, por exemplo, da perspectiva do indivíduo ou da organização. Santos et al. (2009, pg. 134) observam "que 'habilidade' é definida como comportamento ou conjunto de comportamentos (...) e 'competência' refere-se ao grau de eficiência e eficácia desses comportamentos, explicitado de acordo com critérios prévia e socialmente delimitados".

Nesse sentido, para tornar mais precisa a sua função, neste estudo, a competência está subsumida no comportamento humano. Mas o que significa comportamento? Para a maioria das pessoas o comportamento está relacionado à maneira de agir ou à forma de fazer algo. Botomé (2001) realizou uma análise detalhada desse conceito utilizando as contribuições de Skinner (1931, 1935,1938), Pavlov (1934), Staddon (1961), Schick (1971), Catania (1973), Keller e Schoenfeld (1970) e conclui que o comportamento pode ser definido como "uma relação entre o que indivíduo faz (a resposta ou ação) e os ambientes (meios físicos e sociais) antecedente e consequente a esse fazer". (BOTOMÉ, 2001, p.705).

Assim, a ação da recepcionista de um hotel ao cumprimentar um hóspede, por exemplo, está relacionada com as ações do hóspede e com os ambientes físicos que se apresentam antes e depois da ação de cumprimentar. Nos princípios da análise experimental do comportamento, a sistematização de Botomé (2001) indica que o comportamento não ocorre por si só, mas é dependente de estímulos antecedentes e de estímulos consequentes, bem como dos tipos de relações estabelecidas entre esses componentes.

A análise do comportamento, segundo Franceschini (2009), considera que os comportamentos praticados pelos empregados decorrem da interação destes com seu ambiente de trabalho, incluindo-se seus relacionamentos com outros trabalhadores (ambiente social) e com as práticas culturais e empresariais vigentes. Isso pode ser visualizado em estudo realizado por Corrêa e Teixeira (2014) em hotéis e agências de viagens do Estado de Sergipe. A pesquisa dos referidos autores apontou carência de profissionais com as competências necessárias para ocupar as posições de nível operacional, médio ou superior. Todavia, por outro lado, as 
práticas empresariais vigentes deixam a desejar para suprir essa carência, pagando, por exemplo, salários incompatíveis com o nível de qualificação desejado.

Apoiada em Glenn e Mallot (2005), Franceschini (2009) defende que a análise funcional do comportamento deve compreender tanto o comportamento de indivíduos em organizações quanto o comportamento de organizações como entidades funcionais. Para elucidar seu argumento, Franceschini (2009) exemplifica com uma indústria produtora de peças de plástico. O esquema de produção (antecedente) contém instruções ao trabalhador para montar o molde (respostas) para peças plásticas. Um molde finalizado é o produto do comportamento deste operário. O operário coloca o molde em uma empilhadeira para levá-lo à prensa e, se o molde é fixado adequadamente na prensa, a tarefa estará completa (consequência). Porém, se o molde não se encaixar, o operário deve manipulá-lo até que ele se ajuste. A relação entre suas ações e a prensa adequadamente carregada (contingência) afetará a maneira como a fixação do molde será feita da próxima vez (GLENN MALLOT, 2005; FRANCESCHINI, 2009).

Filogeneticamente, segundo Franceschini (2009, p. 116),

o operário herdou a capacidade de adaptar suas respostas em função das consequências, de forma que ele é capaz de aprender. Sua história pessoal moldou e aprimorou esta capacidade tornando-o mais ou menos sensível a determinados estímulos (por exemplo, ao seguimento de regras e instruções) e sua cultura agiu durante toda esta configuração, determinando suas relações sociais e hierárquicas (contato com seu patrão, sua família ou seus colegas), seus reforçadores condicionados (salário, emprego, segurança etc.) e as práticas empresariais vigentes (ex. linha ou esquema de produção sob um sistema capitalista) (Franceschini, 2009, p. 116).

O comportamento humano, segundo a abordagem da análise do comportamento, pode ser representado por três elementos básicos: situação antecedente (o que acontece antes ou junto à ação de um organismo), ação (aquilo que o organismo faz) e as consequências (o que acontece depois da ação de um organismo). Esses três elementos, segundo Botomé (2001, p. 703), "são as relações entre o que o organismo faz e o meio em que o faz que definem o comportamento que está ocorrendo".

Isso pode ser verificado quando um hóspede necessita abrir a porta do quarto de um hotel com um modelo de chave em formato de cartão com chip. A ação do hóspede é inserir o cartão com chip no encaixe da porta. Antecedem essa ação a porta fechada e informações sobre o funcionamento do cartão. As consequências são informações suficientes sobre o funcionamento do cartão e a 
porta aberta. Isso significa dizer que o comportamento não é diretamente observável, mas inferido a partir da identificação das relações dinâmicas entre os elementos do comportamento, as quais podem se modificar caso se alterem as situações do ambiente e as ações do sujeito.

Decorre disso que um comportamento pode ser composto de um conjunto de comportamentos ou classe de comportamentos. De acordo com Kienen e Viecili (2008, p.1) “(...) classe de comportamentos não se refere a um comportamento determinado, mas a comportamentos que podem variar em relação a suas propriedades constituintes, mas que, apesar dessa variação têm a mesma função". Por exemplo, o comportamento de uma recepcionista de "comunicar uma informação a um hóspede" pode ser constituído por "emitir uma informação verbalmente", "emitir uma informação escrita", "emitir uma informação gestualmente", dentre outros. Esses comportamentos possuem a mesma função que o comportamento "comunicar uma informação a um hóspede", porém possuem estímulos diferenciados. Assim, uma classe de comportamentos engloba vários eventos com propriedades semelhantes, responsáveis por fazerem existir determinados tipos de relação.

Um determinado cargo pode ser composto de um conjunto de comportamentos necessários para que as atividades sejam executadas corretamente. Conforme Teixeira (2011), para um profissional gerenciar um hotel é necessária uma variedade de competências técnicas e comportamentais, tais como: conhecimento do tipo negócio, conhecimento administrativo e gerencial, organização, visão de negócio, paciência, habilidade de relacionamento com os hóspedes, liderança, simpatia, flexibilidade, dentre outras. Diante disso, é possível perceber que a execução das atividades de um cargo necessita do conhecimento claro de quais são os comportamentos que o indivíduo deveria apresentar. Quando os comportamentos são identificados é possível planejar ações mais efetivas relacionadas à gestão de pessoas, por exemplo, atrair e selecionar candidatos de acordo com as competências requeridas.

\subsection{0 cargo como produtor de comportamento}

Spector (2002) propõe o método de análise do trabalho para descrever tanto os diferentes tipos de trabalhos quanto as características humanas necessárias para o desenvolvimento das atividades. Segundo esse autor, a análise do trabalho fornece uma imagem precisa das funções, descrevendo os diferentes tipos de atividades pertinentes a um determinado cargo, bem como os requisitos necessários para o seu pleno desenvolvimento. 
Há dois tipos de análise de trabalho, segundo Spector (2002): uma orientada ao trabalho e outra orientada à pessoa. A análise orientada para o trabalho fornece informações sobre as tarefas realizadas no trabalho, descreve as atividades em si, bem como aspectos ergonômicos e de segurança. Já a análise orientada à pessoa fornece uma descrição das competências individuais necessárias para a execução das atividades.

Rabaglio (2004) propõe identificar as competências técnicas e comportamentais de um determinado cargo mediante o mapeamento de competências. A técnica de Rabaglio (2014) pressupõe análise detalhada das atividades do cargo para, em seguida, derivar os conhecimentos (competências técnicas), as habilidades (pré-requisitos do cargo) e as atitudes (competências comportamentais). Após o mapeamento das competências é possível agrupar aquelas que apresentam estímulos semelhantes, criando assim competências genéricas compostas de um conjunto de indicadores de competências da mesma classe de estímulos. Também, nesse caso, o método de análise do trabalho possibilita extrair as competências de um determinado cargo.

O processo de decomposição de comportamentos pode ser uma metodologia para identificar os comportamentos de um cargo. Decomposição de comportamentos, segundo Kienen (2008), significa encontrar as partes constituintes de um todo; no caso de classe de comportamentos, significa encontrar partes constituintes de uma classe de comportamentos que, neste caso, são outras classes de comportamentos. Ou seja, qualquer cargo é constituído de um conjunto de comportamentos que nem sempre são identificados ou conhecidos pelas organizações.

Na investigação dos comportamentos requeridos para uma determinada tarefa, Botomé (1981, 1996a, 1996b) propõe iniciar pela identificação de quais comportamentos deveriam ser ensinados, a partir da caracterização daquilo que o aprendiz já é capaz de realizar. A resposta a essa questão fundamenta os outros comportamentos de uma determinada tarefa, como se exemplifica na Figura 1.

Na Figura 1, a partir da tarefa de dirigir um automóvel de um hóspede até o estacionamento do hotel, são decompostos outros comportamentos constituintes do comportamento inicial. As respostas "arrancar o carro", "fazer manobras corretas", "seguir sinais de trânsito" formam o primeiro grau de decomposição e são denominadas de comportamentos intermediários da classe de comportamento inicial. Quando a pergunta é repetida para o comportamento "arrancar o carro", temos novas respostas, tais como "dar partida no carro", "destravar o carro", "acelerar lentamente", "fazer mudanças de marcha", que constituem um segundo grau 
de decomposição. Os graus de decomposição podem ter continuidade para cada novo comportamento identificado e seguir até o nível de abrangência desejado.

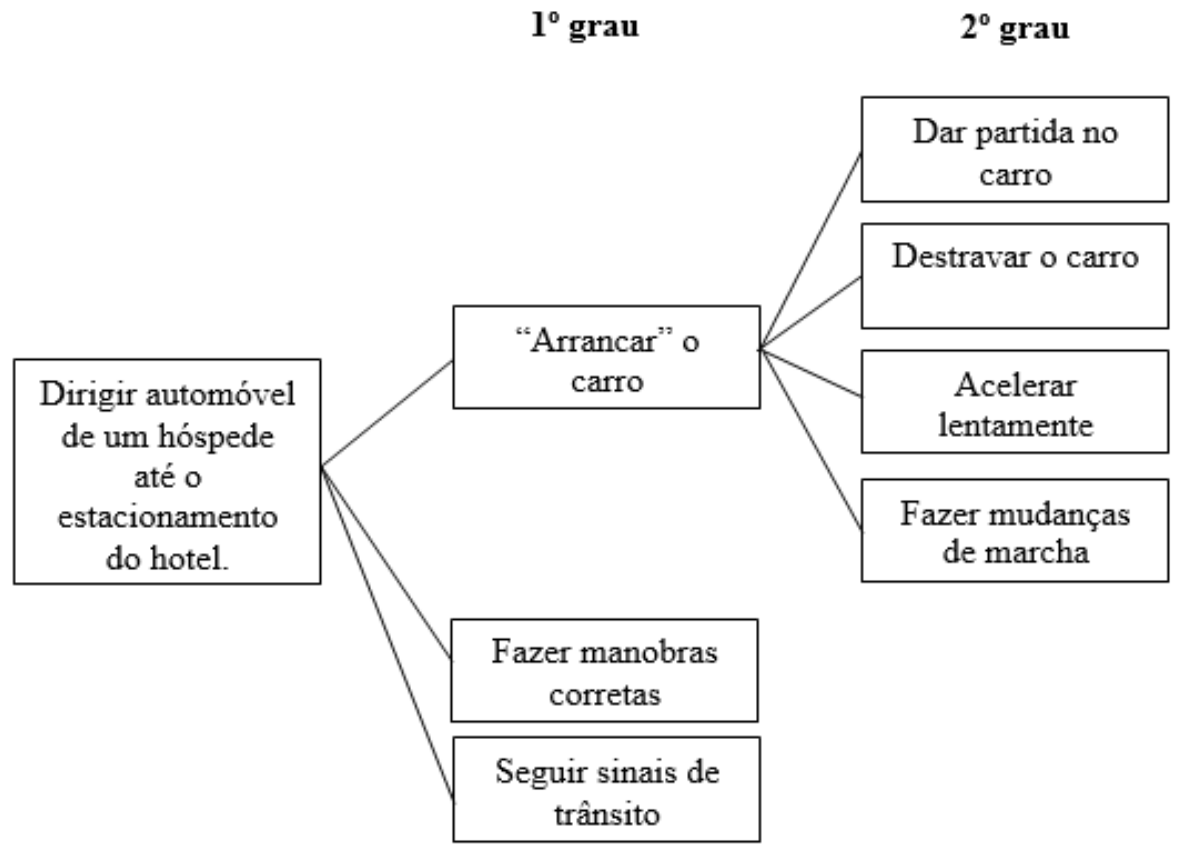

Figura 1: Identificação parcial de comportamentos da tarefa "dirigir automóvel de um hóspede até o estacionamento do hotel" realizada por um profissional no cargo de manobrista. Fonte: Adaptado de Botomé (1996b)

A identificação de comportamentos permite ter um grau de clareza e precisão em relação às aprendizagens esperadas dos empregados para um determinado cargo. Além disso, revela as competências necessárias para execução de um determinado cargo e, também, auxilia nas estratégias relacionadas aos processos de recrutamento e seleção de pessoas, treinamento, bem como do desenvolvimento e avaliação de desempenho dos profissionais de determinados cargos.

\section{Procedimentos Metodológicos}

O delineamento da classe de comportamentos requerida nas vagas abertas para atuar nos meios de hospedagem foi realizado por meio da abordagem qualitativa e quantitativa, pois considerou, nas suas análises, dados objetivos e subjetivos. Caracterizada como pesquisa descritiva, busca descrever as características de um determinado fenômeno e o estabelecimento de relação entre variáveis (Gil, 2010). Nesse sentido, os dados foram registrados, analisados, classificados e 
interpretados de acordo com as variáveis dispostas nos anúncios de vagas de empregos, permitindo aumentar a clareza a respeito do que constitui as vagas e os cargos.

A análise documental de anúncios on line de vagas de empregos conhecidos e de fácil acesso no Brasil se constitui como fonte de dados. A escolha e seleção dos sites considerou uma amostra por acessibilidade ou conveniência e, de acordo com Gil (2010), foram selecionados os elementos a que se tem acesso para representar o universo. Assim sendo, foram escolhidos cinco sites de empregos de abrangência nacional: Sine, Catho, Indeed, Pense Emprego e Manager, conforme se vê no Quadro 1. A coleta de dados foi realizada no período de 13 a 24 de novembro de 2014.

Quadro 1: Fontes de coleta de dados da pesquisa

\begin{tabular}{|l|l|l|}
\hline Fontes & Nome do Site & Endereço do Site \\
\hline 1 & Sine - Site Nacional de Emprego & http://www.sine.com.br \\
\hline 2 & Catho - Empregos e Vagas de Emprego & http://www.catho.com.br \\
\hline 3 & Indeed & http://www.indeed.com.br \\
\hline 4 & Pense Empregos & http://www.penseempregos.com.br \\
\hline 5 & Manager & http://www.manager.com.br \\
\hline
\end{tabular}

Fonte: elaborado pelos autores, com base nos resultados da pesquisa (2015).

A análise dos dados foi realizada em duas etapas. Inicialmente, os dados foram tabulados nas categorias quantidade de anúncios, quantidade de vagas, cidade das vagas, classificação da vaga em nível estratégico, gerencial e operacional, nome do cargo, atividades, nível instrução, experiência, idiomas e classe de comportamentos.

Posteriormente, na segunda etapa, foi realizada a seleção da classe de comportamentos constituintes do cargo. A decomposição da classe de comportamentos foi fundamentada em Botomé (1981), e se constituiu de um processo que envolveu tarefas de dedução e interpretação dos dados, de procura de significados, entendimentos ou sinalizações que designassem os achados do estudo (MERRIAM, 1998). Com base na sistematização de Botomé (1981), o comportamento não é algo diretamente observável, as várias relações entre os componentes das vagas não são identificadas ou acessíveis à observação direta, mas inferidas a partir da identificação das relações estabelecidas entre os componentes das vagas e o que se espera delas, por meio da contratação de um empregado. Mais especificamente, o aspecto principal se refere à investigação das ações requeridas na execução das tarefas de determinados cargos - é por meio da identificação dessas ações que os comportamentos são discernidos ou revelados.

Assim, a decomposição da classe de comportamentos foi realizada mediante resposta para da seguinte questão: $O$ que o candidato precisa estar apto a fazer para conseguir realizar a 
atividade que a vaga requer? As respostas a essa pergunta caracterizaram os comportamentos constituintes do cargo. O procedimento foi realizado até o primeiro nível de abrangência. Após a identificação dos comportamentos constituintes dos cargos, foi realizado um agrupamento dos comportamentos que possuem estímulos semelhantes que resultaram nas classes de comportamentos genéricas e, finalmente, foi elaborada uma definição para a classe de comportamentos inicial. O procedimento realizado pode ser visualizado no Quadro 2.

Quadro 2: Procedimento de decomposição de comportamentos e nomeação da classe de comportamentos genérica dos cargos pesquisados

\begin{tabular}{|c|c|c|c|c|}
\hline Cargo & Atividades & $\begin{array}{l}\text { Comportamentos } \\
\text { constituintes do cargo } \\
\text { (O que o candidato } \\
\text { precisa estar apto a fazer } \\
\text { para conseguir realizar a } \\
\text { atividade?) }\end{array}$ & $\begin{array}{l}\text { Comportamentos } \\
\text { com estímulos } \\
\text { semelhantes }\end{array}$ & $\begin{array}{l}\text { Nomeação da } \\
\text { classe de } \\
\text { comportamentos } \\
\text { Genérica }\end{array}$ \\
\hline $\begin{array}{l}\text { Recepcionista } \\
\text { de Hotel }\end{array}$ & $\begin{array}{l}\text { Atuar com } \\
\text { atendimento ao } \\
\text { cliente, check- } \\
\text { in e out (...) }\end{array}$ & $\begin{array}{l}\text { - Diferenciar hóspede } \\
\text { (check-in ou check-out). } \\
\text { - Falar com diferentes } \\
\text { tipos de pessoas. } \\
\text { - Efetuar check-in e } \\
\text { check-out no menor } \\
\text { tempo possível. } \\
\text { - Falar com dicção } \\
\text { adequada. } \\
\text { - Prestar informações } \\
\text { com clareza pessoalmente } \\
\text { ou via telefone. } \\
\text { - Ouvir com a atenção o } \\
\text { cliente. } \\
\text { - Repassar recados } \\
\text { corretamente (...) }\end{array}$ & \multirow[t]{2}{*}{$\begin{array}{l}\text { - Falar com } \\
\text { diferentes tipos de } \\
\text { pessoas. } \\
\text { - Falar com dicção } \\
\text { adequada. } \\
\text { - Prestar informações } \\
\text { com clareza } \\
\text { pessoalmente ou via } \\
\text { telefone. } \\
\text { - Ouvir com atenção } \\
\text { o cliente. } \\
\text { - Prestar informações } \\
\text { verbalmente sobre o } \\
\text { cardápio ao cliente. }\end{array}$} & \multirow[t]{2}{*}{$\begin{array}{l}\text { Comunicar-se } \\
\text { com o cliente. }\end{array}$} \\
\hline Garçom & $\begin{array}{l}\text { Apresentar o } \\
\text { cardápio ao } \\
\text { hóspede ou } \\
\text { indicar buffet } \\
\text { para servir-se } \\
\text { (...) }\end{array}$ & $\begin{array}{l}\text { - Falar com diferentes } \\
\text { tipos de pessoas. } \\
\text { - Falar com dicção } \\
\text { adequada. } \\
\text { - Identificar os } \\
\text { ingredientes constituintes } \\
\text { nos produtos oferecidos } \\
\text { no cardápio. } \\
\text { - Prestar informações } \\
\text { verbalmente sobre o } \\
\text { cardápio ao cliente. } \\
\text { - Ouvir com atenção o } \\
\text { cliente. } \\
\text { - Identificar hóspede que } \\
\text { não foi atendido (não } \\
\text { recebeu cardápio) (...) }\end{array}$ & & \\
\hline
\end{tabular}

Fonte: elaborado pelos autores, com base nos resultados da pesquisa (2015). 
Essa organização possibilitou identificar categorias de comportamento, a definição da classe de comportamentos e os comportamentos intermediários contituintes da classe de comportamentos inicial. Para as definições das classes de comportamentos foi utilizado o detalhamento da decomposição das vagas.

Note-se que os comportamentos intermediários são decorrentes de todas as vagas pesquisadas, ou seja, não é de uma vaga ou cargo específico, uma vez que o objetivo deste estudo foi identificar classes de comportamentos comuns às vagas e cargos. O que se quer dizer é que seria necessário outro estudo para a definição das classes de comportamentos de cada vaga e cargo específicos.

\section{Análise dos Resultados}

Foram identificados 32 anúncios de vagas de trabalho durante o período de coleta de dados, os quais divulgavam efetivamente 52 vagas. As vagas ofertadas destinavam-se aos Estados de Santa Catarina (29\%), Paraná (27\%), São Paulo (21\%), Rio Grande do Sul (11\%), Ceará (2\%), ao Distrito Federal (8\%) e sem divulgação de estado (2\%). Os estados que concentravam o maior número de vagas eram Santa Catarina e Paraná, totalizando 56\% das vagas, apontando o potencial dos meios de hospedagem na absorção de profissionais na Região Sul.

Aqui é importante ressaltar que essa realidade de vagas identificadas nos sites pode estar relacionada a uma dinâmica específica da rede hoteleira em relação ao processo de recrutamento, no sentido de adotar estratégias não formalizadas de divulgação de vagas, muitas vezes mais rápidas e mais baratas. Segundo estudo de Luz et al. (2011), a "boca a boca" é o método mais utilizado para atrair novos profissionais e se constitui numa espécie de apresentação ou indicação do candidato a partir dos empregados dos estabelecimentos, dos familiares e ou amigos. Dependendo da forma como o processo é conduzido pode incluir uma dinâmica muito particular de convite a funcionários de empresas concorrentes.

Para fins didáticos e considerando a análise das atividades correspondentes, os cargos indicados nas vagas foram classificados de acordo com os níveis estratégicos organizacionais propostos por Oliveira (2012), em nível operacional, tático e estratégico (ver Quadro 3).

Das 52 vagas de trabalho divulgadas, $83 \%$ eram para cargos no nível operacional, caracterizadas como vagas que possuem foco no processo e na execução das atividades e com objetivos de curto prazo, tais como atendimento ao cliente, fechamento do caixa, efetuar 
check-in e check-out, vender bebidas, manobrar carros, dentre outras. Como se lê no referido quadro, os cargos de maior demanda são o de recepcionista e camareira, ambos também do nível operacional.

As vagas classificadas no nível tático perfizeram $8 \%$ do total, caracterizadas em atividades de planejamento e criação de condições adequadas à realização das atividades diárias na esfera operacional, tais como: avaliação dos empregados, acompanhamento da taxa de ocupação média dos meios de hospedagem dos concorrentes, coordenação dos inventários físicos do estabelecimento e controle de custos.

Em posições estratégicas foram identificadas 9\% das vagas, no cargo de gerente, e não foram identificadas vagas de diretores e presidentes. Esse resultado pode ser em decorrência de os empreendimentos serem familiares e a gestão do negócio ir passando de geração para geração, conforme já se identificou em outros estudos, sendo que um deles aponta que " $83 \%$ dos hotéis brasileiros são administrados por seus familiares: o restante (17\%) está ligado a cadeias hoteleiras" (ANDRADE, 2007, p. 31).

Quadro 3: Quantidade de anúncios e vagas de acordo com cargos operacionais, gerenciais e estratégicos

\begin{tabular}{|l|l|c|c|}
\hline \multicolumn{1}{|c|}{ Nome do Cargo } & Nível da vaga & $\begin{array}{c}\text { Quantidade de } \\
\text { anúncios }\end{array}$ & $\begin{array}{c}\text { Quantidade de } \\
\text { vagas }\end{array}$ \\
\hline Recepcionista de hotel & Operacional & 9 & 16 \\
\hline Copeiro & Operacional & 1 & 11 \\
\hline Camareiro & Operacional & 7 & 5 \\
\hline Mensageiro & Operacional & 4 & 4 \\
\hline Cozinheiro & Operacional & 3 & 1 \\
\hline Chefe de recepção & Tático & 1 & 1 \\
\hline Coordenador & Tático & 1 & 4 \\
\hline Governanta & Operacional & 1 & 1 \\
\hline Garçom & Operacional & 1 & 1 \\
\hline Gerente de Alimento e bebidas & Tático & 1 & 1 \\
\hline Steward & Operacional & 1 & 5 \\
\hline Supervisor de andares & Tático & 1 & 52 \\
\hline Gerente de Hotel & Estratégico & 1 & 32 \\
\hline Total de anúncios/total de vagas & & 1 & 1 \\
\hline
\end{tabular}

Fonte: elaborado pelos autores, com base nos resultados da pesquisa (2015). 
Em relação à categoria escolaridade, cujos resultados são representados na Figura 2, o estudo constatou que $73 \%$ das vagas do nível operacional e gerencial primavam pela absorção de profissionais que possuíssem no mínimo ensino médio ou superior, porém somente seis vagas de nível superior solicitavam formação na área de Hotelaria, Turismo e Gastronomia.

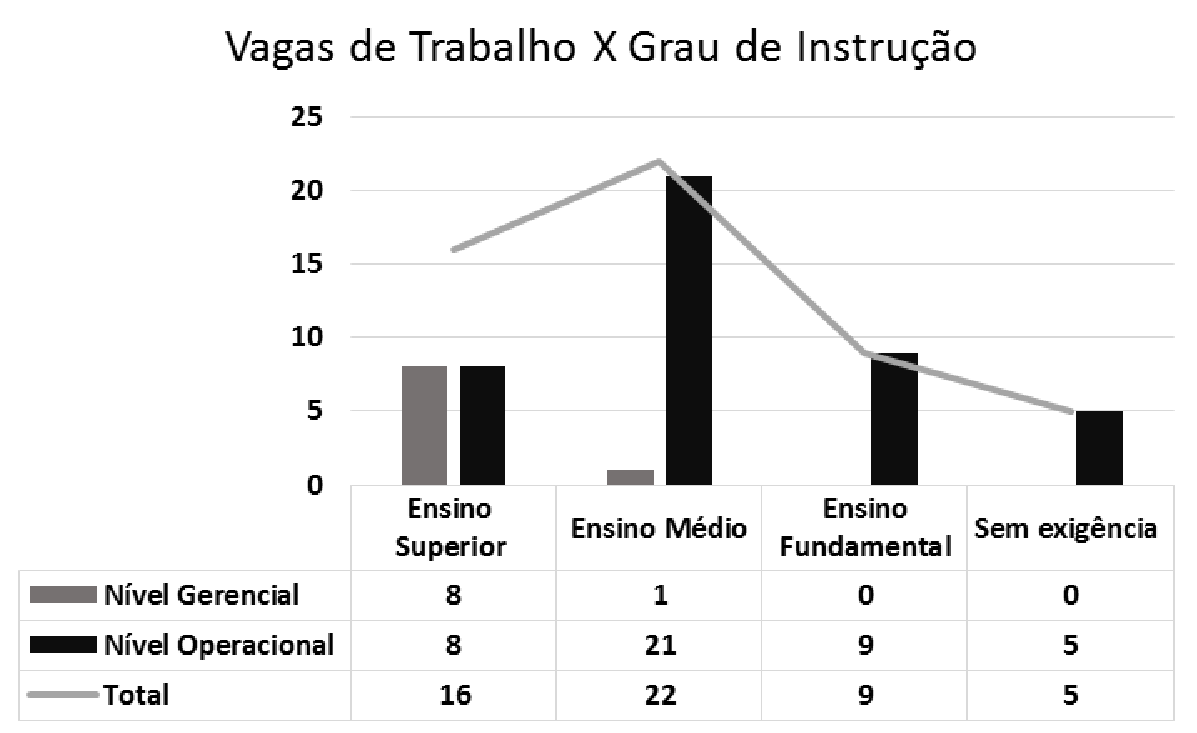

Figura 2: Grau de instrução das vagas de trabalho a nível operacional e gerencial Fonte: elaborado pelos autores, com base nos resultados da pesquisa (2015).

Estudo realizado em 2014 pelo Instituto de Pesquisa Econômica Aplicada (IPEA) constatou que em 2011 a escolaridade dos empregados no turismo era de 7\% até o quinto ano, de $27 \%$ do sexto ao nono ano, de $60 \%$ que concluíram o ensino médio ou com superior incompleto e de $7 \%$ que finalizaram o ensino superior. O estudo analisou que houve evolução do nível de escolaridade em relação aos anos anteriores no turismo, no entanto ainda carece de evolução, em especial no nível superior, que está abaixo da média nacional.

As vagas de nível gerencial demandam um grau de escolaridade maior em virtude das características das atividades desenvolvidas por esse profissional, as quais necessitam do desenvolvimento de uma variedade de competências. Para o gerenciamento de uma equipe, por exemplo, é fundamental o domínio de competências tais como proporcionar feedback aos membros da equipe, fazer reuniões, comunicar-se assertivamente, promover divisão de tarefas, resolver conflitos, estimular sugestões, ouvir, dentre outras. 
Um dos aspectos importantes a serem avaliados nas vagas de trabalho diz respeito à experiência profissional. Entende-se por experiência, segundo Doron e Parot (2002), o conjunto de informações que o ser humano recebe do universo que o cerca, ou seja, o conjunto de suas experiências ou vivências passadas em atividades similares ou correspondentes. Nesse sentido, pode-se entender por experiência profissional o tempo de atuação em determinada atividade ou ramo. Das vagas pesquisadas (Figura 3), 61,5\% das organizações desejavam que o profissional possuísse experiência profissional nas atividades que iria executar ou no ramo da hospitalidade, e apenas 38,5\% não exigiam experiência. Esse resultado incentiva a aprendizagem no trabalho e novas oportunidades, após contratação. Segundo dados do Sebrae (2014, p. 47) a maioria dos destinos turísticos do Brasil apresenta "deficiências na formação da mão de obra, como falta de conhecimento de outros idiomas, de capacitação técnica e até mesmo de noções de higiene".

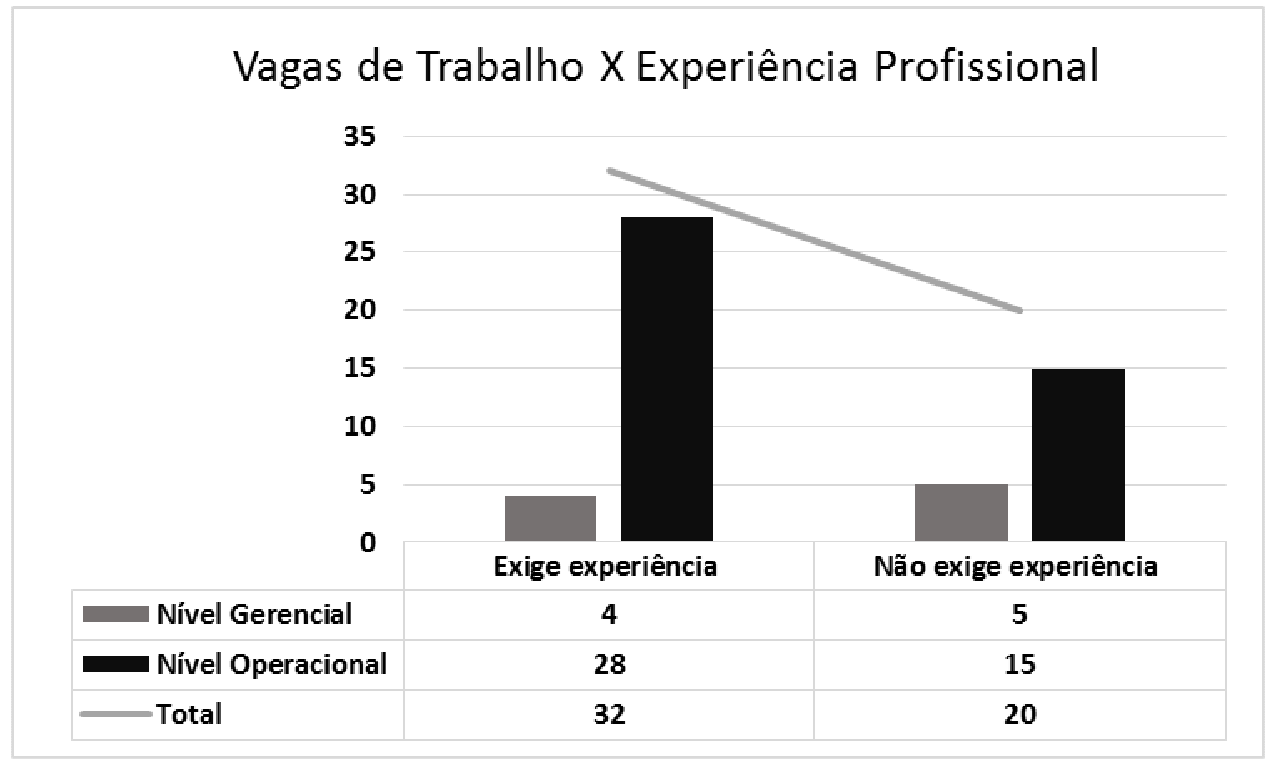

Figura 3: Experiência profissional das vagas de trabalho

Fonte: elaborado pelos autores, com base nos resultados da pesquisa (2015).

O que se lê em alguns estudos é que uma das competências requeridas aos profissionais que atuam na área do turismo e hospitalidade é o domínio de outros idiomas, em virtude de que seu cliente pode ser oriundo de vários países. De acordo com dados apresentados por Chagas e Fernandes (2010), a maior necessidade de qualificação solicitada pelos profissionais que atuam na rede hoteleira é em relação aos cursos de línguas. 
Todavia, das vagas de trabalho analisadas neste estudo, somente $27 \%$ requeriam que o profissional tivesse conhecimento de outros idiomas, como pode ser visto na Figura 4. As vagas com maior exigência de um segundo ou terceiro idioma eram as vagas a nível gerencial e as vagas de recepcionista. Os idiomas solicitados eram o inglês e o espanhol, em nível intermediário e avançado. Esses dados corroboram com a pesquisa realizada por Blanco, Leão e Guzzo (2013) sobre as respostas de e-mails para efetuar reservas nos meios de hospedagem, nos idiomas inglês, espanhol e português. Os autores verificaram que $68 \%$ dos retornos eram em português, $60 \%$, em espanhol e apenas $49 \%$ dos retornos eram em inglês. Isso demonstrou dificuldade dos atendentes em relação às línguas.

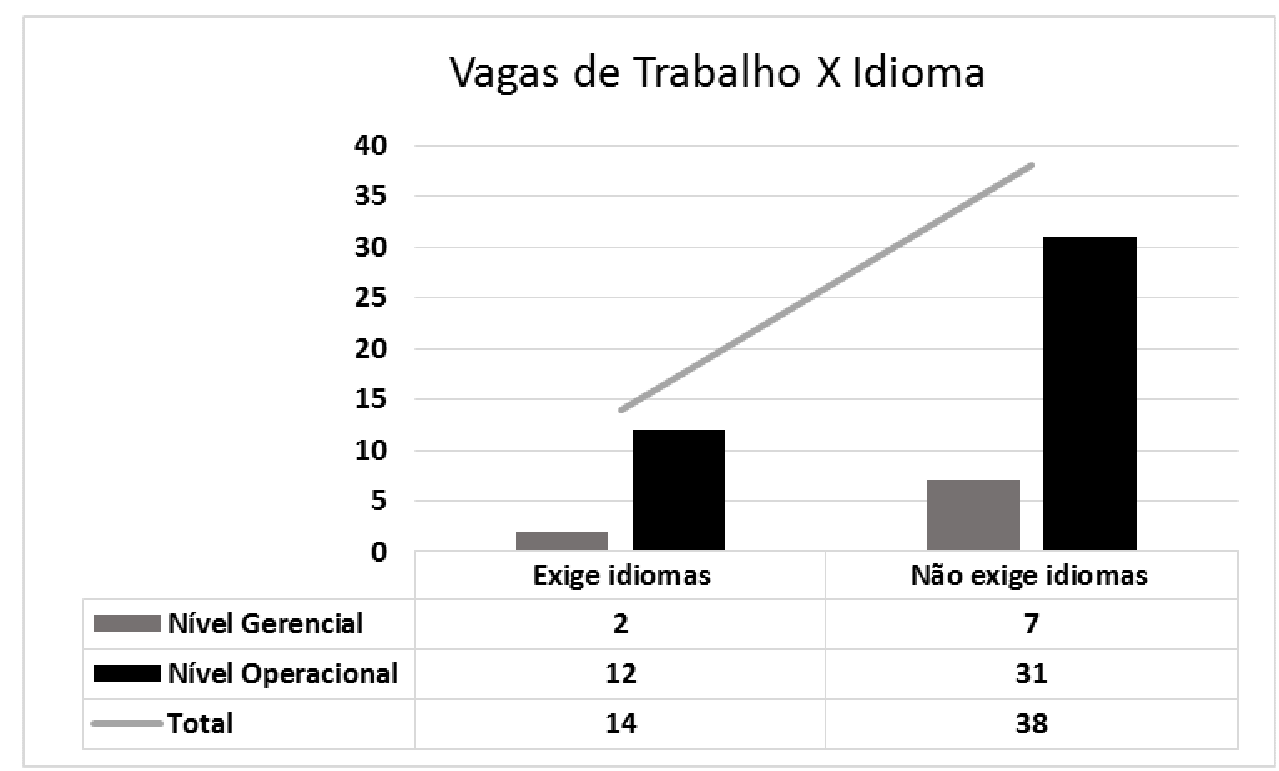

Figura 4: Vagas de trabalho que exigiam conhecimento de outro idioma Fonte: elaborado pelos autores, com base nos resultados da pesquisa (2015).

O estudo identificou 10 classes requeridas de comportamentos para a execução das atividades referentes aos cargos indicados nas vagas. As classes de comportamentos comuns às vagas identificadas são: comunicar-se com o cliente, relacionar-se com o cliente, agir com proatividade, organizar as atividades, atuar com agilidade, concentrar-se para solução de problemas, trabalhar em equipe, planejar ações, realizar as atividades técnicamente e liderar com foco para o resultado. As classes de comportamentos identificadas são comuns às vagas de nível operacional, tático ou gerencial, exceto a classe de comportamentos liderança, pois a mesma está relacionada somente às vagas gerenciais. Cabe ressaltar que foram identificadas 
outras classes de comportamentos específicas para cada cargo, mas que não serão citadas neste estudo.

No Quadro 4 apresentam-se a classe de comportamentos inicial (génerica), a definição da classe de comportamentos e os comportamentos intermediários contituintes da classes de comportamentos inicial. Os exemplos dos comportamentos intermediários são de todas as vagas pesquisadas, ou seja, não é de uma vaga ou cargo específico. Cabe ressaltar que o objetivo deste estudo foi identificar classes de comportamentos comuns às vagas e aos cargos correspondentes oferecidos para atuar nos meios de hospedagem, e seriam necessários outros estudos para a definição das classes de comportamentos de cada vaga e cargo. O símbolo “(...)" sinaliza que a identificação dos comportamentos derivados tem continuidade.

Quadro 4: Classe de comportamentos comuns às vagas de trabalho para atuar nos meios de hospedagem

\begin{tabular}{|c|c|c|}
\hline $\begin{array}{c}\text { Classe de } \\
\text { comportamentos }\end{array}$ & $\begin{array}{c}\text { Definição da classe de } \\
\text { comportamentos }\end{array}$ & $\begin{array}{c}\text { Comportamentos intemediários relacionados à } \\
\text { classe de comportamento incial }\end{array}$ \\
\hline $\begin{array}{l}\text { Comunicar-se com } \\
\text { o cliente }\end{array}$ & $\begin{array}{l}\text { Interagir com uma } \\
\text { variedade de tipos de } \\
\text { clientes }\end{array}$ & $\begin{array}{l}\text { - Falar com diferentes tipos de pessoas. } \\
\text { - Falar com dicção adequada. } \\
\text { - Prestar informações com clareza pessoalmente ou } \\
\text { via telefone. } \\
\text { - Ouvir com atenção o cliente. } \\
\text { - Repassar recados corretamente (...) }\end{array}$ \\
\hline $\begin{array}{l}\text { Relacionar-se com } \\
\text { o cliente }\end{array}$ & $\begin{array}{l}\text { Estabelecer relação com } \\
\text { o cliente verbalmente ou } \\
\text { gesticuladamente }\end{array}$ & $\begin{array}{l}\text {-Respeitar os clientes independente de suas } \\
\text { diferenças individuais. } \\
\text { - Executar as atividades auxiliando o cliente. } \\
\text { - Recepcionar hóspedes/clientes no balcão. } \\
\text { - Direcionar os hóspedes para as áreas desejadas do } \\
\text { hotel (...) }\end{array}$ \\
\hline $\begin{array}{l}\text { Agir com } \\
\text { proatividade }\end{array}$ & $\begin{array}{l}\text { Antecipar as ações } \\
\text { decorrentes do ambiente }\end{array}$ & $\begin{array}{l}\text { - Mediar conflitos nas dependências do hotel. } \\
\text {-Intervir em situações críticas/atípicas, junto aos } \\
\text { clientes/hóspedes. } \\
\text { - Acompanhar as solicitações do cliente. } \\
\text { - Solucionar problemas antes de afetarem o cliente. } \\
\text { - Observar as mesas e perceber quando o hóspede } \\
\text { necessita de reposição ao serviço e limpeza da mesa } \\
(\ldots)\end{array}$ \\
\hline $\begin{array}{l}\text { Organizar as } \\
\text { atividades }\end{array}$ & $\begin{array}{l}\text { Instituir ou seguir } \\
\text { padrões orientativos }\end{array}$ & $\begin{array}{l}\text { - Efetuar check-in e check-out, de acordo com as } \\
\text { normas e orientações do hotel. } \\
\text { - Receber documentos e dar os destinos corretos. } \\
\text { - Montar as mesas do restaurante obedecendo o } \\
\text { padrão estabelecido pelo hotel. } \\
\text { - Manter em ordem as áreas do hotel. } \\
\text { - Organizar os itens e aparelhos referentes ao } \\
\text { serviço de copa (...) }\end{array}$ \\
\hline
\end{tabular}




\begin{tabular}{|c|c|c|}
\hline $\begin{array}{l}\text { Atuar com } \\
\text { agilidade }\end{array}$ & $\begin{array}{l}\text { Executar as atividades } \\
\text { com rapidez ou de } \\
\text { maneira acelerada }\end{array}$ & $\begin{array}{l}\text { - Efetuar check-in e check-out no menor tempo } \\
\text { possível. } \\
\text { - Levar as bagagens de hóspede até os quartos. } \\
\text { - Abastecer os quartos com os produtos necessários. } \\
\text { - Preparar pratos de alimentação solicitados pelos } \\
\text { clientes (...) }\end{array}$ \\
\hline $\begin{array}{l}\text { Concentrar-se para } \\
\text { solução de } \\
\text { problemas }\end{array}$ & $\begin{array}{l}\text { Perceber e selecionar } \\
\text { estímulos do ambiente, } \\
\text { estabelecer relação entre } \\
\text { os mesmos }\end{array}$ & $\begin{array}{l}\text { - Manobrar os carros. } \\
\text { - Efetuar fechamento de caixa. } \\
\text { - Efetuar reservas e lançar no sistema. } \\
\text { - Realizar o fechamento das faturas. } \\
\text {-Receber os pagamentos das faturas } \\
(\ldots)\end{array}$ \\
\hline $\begin{array}{l}\text { Trabalhar em } \\
\text { equipe }\end{array}$ & $\begin{array}{l}\text { Compartilhar, dividir as } \\
\text { responsabilidades das } \\
\text { atividades }\end{array}$ & $\begin{array}{l}\text { - Auxiliar os colegas na execução das atividades. } \\
\text { - Auxiliar colegas na resolução de conflitos e nas } \\
\text { dificuldades. } \\
\text { - Buscar entender sentimentos e emoções dos } \\
\text { colegas. } \\
\text { - Fornecer apoio aos colegas (...) }\end{array}$ \\
\hline Planejar ações & $\begin{array}{l}\text { Capacidade de prever } \\
\text { necessidades/atividades } \\
\text { futuras }\end{array}$ & $\begin{array}{l}\text { - Estabelecer ordem de prioridade das atividades. } \\
\text { - Controlar os indicadores relacionados à atividade } \\
\text { de atuação. } \\
\text { - Desenvolver estratégias para o negócio. } \\
\text {-Apresentar as propostas de melhorias } \\
\text { (...) }\end{array}$ \\
\hline $\begin{array}{l}\text { Realizar as } \\
\text { atividades } \\
\text { tecnicamente }\end{array}$ & $\begin{array}{l}\text { Conhecer as } \\
\text { especificidades técnicas } \\
\text { de cada cargo }\end{array}$ & $\begin{array}{l}\text { - Identificar os ingredientes constituintes nos } \\
\text { produtos oferecidos no cardápio. } \\
\text { - Identidicar procedimento para realização de } \\
\text { check-in e check-out. } \\
\text { - Operar programas de informática e controle. } \\
\text { - Identificar procedimento de higienização. } \\
\text { - Identificar os ingredientes para a elaboração de } \\
\text { pratos. }\end{array}$ \\
\hline $\begin{array}{l}\text { Liderar com foco } \\
\text { para o resultado } \\
\text { (Competência } \\
\text { identificada nos } \\
\text { cargos gerenciais) }\end{array}$ & $\begin{array}{l}\text { Estimular e orientar as } \\
\text { pessoas para a execução } \\
\text { das atividades }\end{array}$ & $\begin{array}{l}\text { - Orientar a equipe de acordo com as atividades a } \\
\text { serem realizadas. } \\
\text { - Avaliar os membros da equipe. } \\
\text { - Realizar reuniões. } \\
\text { - Acompanhar e cobrar os resultados nas formas e } \\
\text { prazos estabelecidos. } \\
\text { - Contribuir para a manutenção e motivação dos } \\
\text { recursos humanos (...) }\end{array}$ \\
\hline
\end{tabular}

Fonte: elaborado pelos autores com base nos resultados da pesquisa (2015).

Além de representarem um conjunto de comportamentos necessários para a atuação nos meios de hospedagem, as classes de comportamentos identificadas neste estudo fornecem subsídios aos processos de seleção, treinamento e desenvolvimento de pessoas. Quando a derivação de comportamentos é realizada de maneira precisa para cada cargo, aumentam as probabilidades de conhecimento em relação aos comportamentos que um empregado precisa apresentar no ambiente de trabalho, na execução das atividades de determinado cargo. 
O estudo constatou que o perfil do profissional que atua nos meios de hospedagem tem como foco a gestão dos serviços, ou seja, necessidade de contratar profissionais que não estejam somente preocupados com a aprendizagem de procedimentos e técnicas relacionados ao cargo, mas que estejam buscando aperfeiçoamento em aspectos relacionados aos comportamentos, como, por exemplo, trabalhar em equipe. Diante disso, verifica-se uma necessidade de os profissionais na rede hoteleira buscarem qualificação além dos aspectos técnicos. Isso sinaliza a preocupação da rede hoteleira em prestar serviços de qualidade, mas que acima de tudo estejam adequados às necessidades do seu cliente.

\section{Conclusões e Recomendações}

Este estudo delineou as competências profissionais requeridas na execução das tarefas dos trabalhadores que atuam nos meios de hospedagem, por meio da decomposição da classe de comportamentos que determinado cargo demanda. Conhecer as competências profissionais e os comportamentos requeridos para um determinado cargo, no ramo de negócio dos meios de hospedagem, gera vantagem competitiva e sustentabilidade no mercado. Além disso, permite estruturar ações estratégicas de gestão de pessoas, otimizar o processo de atração e seleção de profissionais e qualificar os profissionais de acordo com as competências pré-definidas de cada cargo.

O estudo revelou uma quantidade de vagas expressiva para atuação nos meios de hospedagem, demonstrando o potencial de crescimento no ramo, embora nem todas as vagas exigissem formação na área. As vagas operacionais, como as de garçom, cozinheiro e camareira, também não solicitavam qualificação profissional nos domínios correspondentes, caracterizando carência de recursos humanos especializados na área. A pouca exigência de um segundo e terceiro idiomas corrobora essa afirmação.

As nove classes de comportamentos elucidadas no estudo das vagas de trabalho evidenciam quais são os comportamentos esperados dos profissionais para atuar nos meios de hospedagem. Assim, a produção de conhecimento acerca das competências profissionais requeridas para atuar nos meios de hospedagem possibilitou maior visibilidade sobre os comportamentos necessários para a execução de atividades de um cargo. A continuidade dessa produção de conhecimento é necessária e fundamental, pois o estudo realizado não identificou as competências profissionais específicas de cada cargo. É importante também 
salientar que o estudo não verificou se as informações apresentadas nos anúncios das vagas são de fato exigidas e requeridas durante o processo de seleção. Ao mesmo tempo em que isso denota uma limitação deste estudo, se apresenta como sugestão de tema para novas investigações.

\section{Referências}

ANDRADE, N.; BRITO, P. L. de; JORGE, W. E. Hotel: Planejamento e projeto. 9 ed. São Paulo: Senac, 2007.

BOTOMÉ, S. P. Sobre a noção de comportamento. In: FELTES, H. P. de M.; ZILLES (orgs). Filosofia: diálogos de horizontes. Porto Alegre: Editora da Pontifícia Universidade Católica de Porto Alegre, 2001, v. 1, p. 685-708.

. Um procedimento para encontrar os comportamentos que constituem as aprendizagens envolvidas em um objetivo de ensino. Manuscrito não publicado. Universidade Federal de São Carlos 1996a.

Repertório de entrada dos aprendizes para um programa de ensino. Manuscrito não publicado. Universidade Federal de São Carlos. 1996b.

BOTOMÉ, S.P.; KUBO, O.M. Responsabilidade social dos programas de pós-graduação e formação de novos cientistas e professores de nível superior. Interação em Psicologia, 6(1), 81-110, 2002.

CHAGAS, M. M.; FERNANDES, G. A. Avaliação dos Impactos socioeconômicos gerados pelo setor hoteleiro. Uma análise dos hotéis da Via Costeira, Natal, RN. Anais VI Seminário de Pesquisa em Turismo no MERCOSUL - SeminTUR. Saberes e fares no turismo: interfaces. Universidade de Caxias do Sul, RS, 9 e 10 de julho, 2010.

CORREAA, J.M.F.G.; TEIXEIRA, R.M. Demanda e Competências dos Profissionais: estudo em agências de viagens e hotéis em Aracaju, Sergipe. Turismo em Análise, v. 25, n. 2, agosto, 2014.

FERNANDES, L. R. Estudo da necessidade de formação profissional dos trabalhadores operacionais da rede hoteleira de Itajaí e Balneário Camboriú. Anais VI Seminário de Pesquisa do Turismo do Mercosul. Caxias do Sul. Brasil, 2010.

FLEURY, M. T. L. et al. A importância das competências individuais para o mundo globalizado: os casos Citibank, Copesul e WEG. In: FICHER, André L (org.) et al. Gestão de Pessoas: desafios estratégicos das organizações contemporâneas. São Paulo: Atlas, 2009.

FRANCESCHINI, A. Psicologia Organizacional e a Análise do Comportamento. TransForm. Psicol. (Online), São Paulo, v.2, n.2, p. 114-125, 2009. Disponível em: $<$ http://pepsic.bvsalud.org/scielo.php?script=sci_arttext\&pid=S2176-

106X2009000200007\&lng=pt\&nrm=iso >. Acesso em: 16 maio 2015.

GIL, A.C. Métodos e técnicas de pesquisa social. 6 ed. São Paulo: Atlas, 2010.

GLENN, S.S.; MALLOT, M. A. Complexidade e Seleção: Implicações para a Mudança Organizacional. In: TODOROV, J. C.; MARTONE, R. C.; MOREIRA, M. B. Metacontingências: Comportamento, Cultura e Sociedade (pp. 101-119). Santo André: ESETec, 2005.

IPEA - Instituto De Pesquisa Econômica Aplicada. Perfil da mão de obra no turismo no Brasil nas atividades características do turismo e ocupações. Brasília: Rio de Janeiro: Ipea, 2014. 
ISAMBERT-JAMATI, V. O apelo à noção de competência na revista L'orientation scolaire et professionelle - Sua criação aos dias de hoje. In: F. Ropé \& L. Tanguy (Orgs.), Saberes e Competências: o uso de tais noções na escola e na empresa. (pp. 5-20). Campinas: Papirus, 1997.

KIENEN, N. Classes de comportamentos profissionais do psicólogo para intervir, por meio de ensino, sobre fenômeno e processos psicológicos, derivadas a partir das diretrizes curriculares, da formação desse profissional e de um procedimento para decomposição de comportamentos complexos. 2008. Tese (Doutorado em Psicologia). Universidade Federal de Santa Catarina, Florianópolis, 2008.

LE BORTEFF, G. De la compétence. Paris: Les Editions D`Organization, 1994.

LUZ, T. R. da; CARRIERI, A.P.; PEREIRA, M.C. Práticas de gestão de pessoas nos caminhos da estrada real. Revista Turismo Visão e Ação - Eletrônica, v. 13, n. 1, p. 96-114, jan-abr 2011.

Disponível em: http://www6.univali.br/seer/index.php/rtva/article/view/2161/1867. Acesso em: 21 jan 2016.

MENEZES, E. T; SANTOS, T. H. . "Classes multisseriadas" (verbete). Dicionário Interativo da Educação Brasileira - EducaBrasil. São Paulo: Midiamix Editora, 2002. Disponível em: <http: www.educabrasil.com.br/dicionario>. Acesso em: $10 \mathrm{dez} 2014$.

MERRIAM, S.B. Qualitative research and case study applications in education. San Francisco: Jossey-Bass, 1998.

OLIVEIRA, D. P. R. de. Planejamento estratégico: conceitos, metodologias e práticas. 17.ed. SÃO PAULO: Atlas, 2002.

PARRY, S. B. The quest of competencies. Training, 1996.

PERRENOUD, P. Dez novas competências para uma nova profissão. In Pátio. Revista pedagógica.

Porto Alegre, Brasil, n. 17, Maio-Julho, p. 8-12, 2001.

RABAGLIO, M. O. Ferramentas de avaliação de performance com foco em competências. Rio de Janeiro: Qualitymark, 2004.

RELATÓRIO BRASIL 2014. Índice de competitividade do turismo nacional: destinos indutores do desenvolvimento turístico regional. Coordenação Luiz Gustavo Medeiros Barbosa. Brasília, DF: SEBRAE, 2014.

SANTOS, G.C.V. dos; KIENEN, N.; VIECILI, J.; BOTOMÉ, S.P.; KUBO, O.M. Habilidades e competências a desenvolver na capacitação de psicólogos: uma contribuição da análise do comportamento para o exame das diretrizes curriculares. Interação em Psicologia, 13(1), p. 131-145, 2009.

SPECTOR, P. E. Psicologia nas organizações. $2^{\circ}$ ed. São Paulo: Saraiva, 2002.

TEIXEIRA, R. M. Competências e Aprendizagem de Empreendedores/Gestores de Pequenas Empresas no Setor Hoteleiro. Turismo em Análise, v. 22, n. 1, abril 2011.

Nota: Agradecemos aos alunos de iniciação científica da Faculdade Senac Chapecó, Eliézer Gabriel, Rakel Fagundes e Monike Maciel, que participarem do levantamento dos dados da pesquisa.

\section{Recebido em: 06/07/2015 (1 ${ }^{\text {a }}$ versão) $14 / 12 / 2015$ ( $2^{\mathrm{a}}$ versão)}

Aprovado em: 21/12/2015 